\title{
ENSINO A DISTÂNCIA: Novos conceitos pedagógicos são necessários ou os conceitos que já existem são suficientes?
}

\author{
Luiz Alberto Brettas* \\ João Artur de Souza ** \\ Elton Luiz Vergara Nunes *** \\ Gertrudes Aparecida Dandolini ${ }^{* * * * *}$ \\ Édis Mafra Lápolli ${ }^{* * * * *}$
}

Resumo: Neste artigo, através da análise dos discursos de alguns pensadores das áreas de Educação (em geral) e de Ensino a Distância, mostramos que, conquanto o Ensino a Distância apresente novos desafios aos professores, o que está por trás de boa parte desses desafios é a necessidade do rompimento com velhas concepções de ensino, o que já é necessário no ensino presencial, como a de entender o processo de ensino como uma transmissão de conhecimentos. Nessa direção, apontamos algumas relações que aparecem em evidência (e algumas subjacentes) nos diferentes discursos dos pensadores dessas duas áreas. Entendemos, a partir dessa análise, que os fundamentos do processo educativo do Ensino a Distância são os mesmos do ensino presencial. Assim, defendemos que, longe de apresentar barreiras intransponíveis à adequada aprendizagem, o Ensino a Distância apresenta oportunidades de aprendizagem para os próprios educadores que com ele se envolverem, uma vez que, por suas características especiais, muitos aspectos do processo de ensino-aprendizagem que se mascaram no ensino presencial (mas que a ele são inerentes) salientam-se no Ensino a Distância, como os relacionados às dificuldades nas comunicações entre alunos e professores. Palavras-chave: Ensino a Distância. Ensino presencial. Relações entre ensino a distância e ensino presencial.

In this article, through the analysis of the speeches of some thinkers of the areas of Education (in general) and Distance Teaching, we show that, besides Distance Teaching presents new challenges to the professors, what is for backwards of good part of these challenges is the necessity of the disruption with old conceptions of education, what already is necessary in actual education, as to understand the education process as a transmission of knowledge. In this direction, we point some relations that appear in evidence (and some underlying ones) in the different speeches of the thinkers of these two areas. We understand, from this analysis, that the beddings of the educative process in distance teaching are the same ones of actual education. Thus, we defend that, far of presenting unsurmountable barriers to the adequate learning, Distance Teaching presents chances of learning for educators themselves who with it if to involve, a time that, for its characteristics special, many aspects of the teach-learning process that, while they mask in actual education (but that is inherent to it) are outstanding in the Distance Teaching, as those related to the difficulties in the communications between pupils and the professors.

\footnotetext{
* Professor, Bacharel em Matemática (UFRGS) e Doutor em Engenharia de Produção (UFSC), Professor de Matemática da UFPEL, labr@brturbo.com.br

** Professor, Licenciado em Matemática (UFSC) e Doutor em Engenharia de Produção na área de Inteligência Artificial (PPGEP/UFSC), Professor de Matemática e Coordenador do Curso de Matemática a Distância da UFPEL, jgartur@brturbo.com.br

${ }^{* * * *}$ Professor, Mestre em Educação (FAE/UFPEL), Professor de Letras/Espanhol da UFPEL, vergaranunes@gmail.com

**** Professora, Licenciada em Matemática (UFSC) e Doutora em Engenharia de Produção na área de Inteligência Artificial (PPGEP/UFSC), Professora de Matemática e Coordenadora do Curso de Matemática da UFPEL, ggtude@gmail.com

*..- Doutora em Engenharia de Produção, Professora do Programa de Pós-graduação em Engenharia de Produção da UFSC.

V. $3 \mathrm{~N}^{\circ} 1$, Maio, 2005
} 


\section{Introdução}

No mundo todo, pensadores têm-se voltado à questão da educação. Os mais diversos aspectos dessa questão (políticos, de fundamentação pedagógica, de práticas de ensino, etc.) têm ocupado espaços cada vez maiores nas edições de revistas e livros científicos.

Esse fato não deve representar algo espantoso para professor algum, uma vez que a educação representa uma chave para a sobrevivência humana.

A capacidade de entendermos o mundo a nossa volta, de interferir nos processos naturais e criar novos processos que possam alterar possíveis realidades futuras e de avaliar resultados dessas interferências e criações foram características que nos permitiram chegar até onde chegamos em ciência e tecnologia.

Por outro lado, apesar dos avanços da humanidade em ciência e tecnologia, no Brasil ainda temos grandes problemas no que diz respeito à formação de nossos cidadãos. Na Educação básica, o Brasil passa, ainda, por uma dura realidade. Para ilustrar isso, cite-se que o aproveitamento escolar no primeiro grau, em 1993, girava em torno de 30\% (Demo, 1993). Isso representa, no mínimo, um imenso desperdício de recursos humanos e materiais. De acordo com os dados do Sistema Nacional de Avaliação da Escola Básica (Saeb) em 2001, 59\% dos alunos brasileiros da $4^{\text {a }}$ série do ensino fundamental não haviam desenvolvido competências elementares de leitura e $52 \%$ demonstravam profundas deficiências em Matemática. Ainda, de acordo com o Saeb, apenas $6 \%$ dos alunos tem o nível desejado1 em matemática (Araújo ${ }^{2} \& \mathrm{Nildo}^{3}$, 2004). Existe uma necessidade de continuar a formação desses professores, não só atualizando-os em seus materiais e métodos como permitindo que os mesmos melhorem sua compreensão do processo educativo, através do aprofundamento dos estudos de diferentes concepções de ensino.

Grande parte da população brasileira vive em locais distantes dos grandes centros educativos. Assim, despontou, nos últimos anos, a alternativa de se oferecerem, com mais frequiência e com maior diversidade, cursos a distância.

Em alguns países do mundo, como Estados Unidos, Reino Unido e Índia, por exemplo, já utilizam essa modalidade de oferta de ensino há muitos anos com sucesso. Nesses países, são oferecidos por algumas universidades, inclusive, cursos de graduação com reconhecimento oficial.

No Brasil, as universidades têm de superar alguns entraves oficiais, como os ligados às estruturas burocráticas dessas instituições, ainda voltadas, quase que totalmente, ao ensino na modalidade presencial, para poderem oferecer cursos de graduação a distância que sejam reconhecidos pelo MEC.

Pensamos que, mais do que o respeito às leis para formação de profissionais de nível superior, existe um preconceito muito grande por parte da comunidade acadêmica contra essa modalidade de ensino.

No Brasil, ainda existe a crença de que o produto do EaD pode não ser sério, de que essa modalidade de ensino não seja eficiente nem eficaz, uma vez que inexiste uma "cultura de autoditatismo" no terceiro mundo. Entendemos que esse preconceito está ligado fortemente às concepções de ensino que norteiam a prática pedagógica de grande

\footnotetext{
${ }^{1}$ Segundo os Parâmetros Curriculares Nacionais.

${ }^{2}$ Diretor de Avaliação da Educação Básica do Instituto Nacional de Estudos e Pesquisas Educacionais Anísio Teixeira (INEP/MEC)

${ }^{3}$ Assessor da Diretoria de Avaliação da Educação Básica do INEP 
parte de nossos professores. Nas Universidades, espraiam-se discursos pedagógicos que apresentam os estudantes como os verdadeiros agentes da aprendizagem e os professores como responsáveis em proporcionar que ela aconteça. No entanto, práticas de sala de aula (do ensino presencial) mostram que os alunos ainda são vistos (exceto por algumas exceções) como recipientes com espaços vazios à espera de novos conhecimentos a serem fornecidos por seus professores. Isso tem levado muitos professores a fracassarem em sua tarefa de ensinar.

Assim, cultua-se a suspeita de que, se com a proximidade física com o aluno o professor já tem dificuldades em executar bem seu trabalho, tentar fazer isso a distância parece tarefa muito pouco produtiva. Desde as primeiras séries do Ensino Fundamental até o Ensino Médio, os professores levam os alunos a se tornarem dependentes das respostas (sempre à espera de exemplos prontos) dos professores. Parece-nos pouco provável que esses professores tenham uma postura aberta à possibilidade do EaD, uma vez que, como bem enfatiza Preti (1996), um dos elementos constitutivos do mesmo é o estudo individualizado e independente.

Parece claro que um ensino que precisa acontecer sem a proximidade física do professor com seus alunos exija algo mais do que a formação que a maioria dos professores têm atualmente.

Alonso (2000) apresenta, com base nas reflexões de Shale (1990), duas ordens de valores que determinam o processo educacional: a comunicacional, para o estabelecimento do diálogo e a da avaliação, para tornar esse processo efetivo.

Com base, ainda, nessas reflexões, afirma que, para que a EaD seja definida como um processo educativo ela deverá

ser pensada como um projeto político-pedagógico que considere em sua base a criação de sistemas

que venham a estabelecer processos comunicacionais que permitam a interação de alunos e

professores, e processos de acompanhamento e avaliação que promovam o ensino/aprendizagem.

Além disso, esses sistemas devem considerar as possibilidades de construção de saberes orientados e pertinentes às diferentes situações dos sujeitos da aprendizagem. ...a organização educativo deverá estar, necessariamente, à disposição dos alunos. (Alonso, 2000)

Observamos que no ensino a distância a comunicação entre professor e alunos e entre os alunos tende a ser mais difícil. Pode ser necessário o uso de telefones, correio tradicional e Internet, ou outras vias mais sofisticadas. Nos processos de Ensino a Distância, a mediação tecnológica é parte integrante da comunicação educativa, o que não implica nenhuma outra particularidade na natureza e importância que a comunicação interpessoal sempre teve e terá, se pensarmos em outras formas de socialização.

Ao aceitar que o vínculo pedagógico, que o diálogo acadêmico entre docentes e estudantes é o elemento de maior densidade e, portanto, nuclear em qualquer processo formativo, não é difícil pensar na transcendência que a comunicação, seja face-a-face ou mediada tecnologicamente, tem na relação educativa e de suas conseqüências nos âmbitos metodológicos e institucional. (Alonso, 2000) 
Com respeito à questão da avaliação, também podemos ter algumas restrições. Como exemplo, podemos citar a dificuldade do educador acompanhar o processo de aprendizagem para poder analisar como e o que o aluno realmente está aprendendo. No caso presencial, o professor pode acompanhar o desenvolvimento dos alunos e perceber quando algo de importante está acontecendo com algum aluno (dificuldades de se concentrar, por exemplo). No Ensino a Distância, essa alternativa raramente existe. Sobra a opção de se acompanhar o aluno em comunicações com o mesmo por outros meios (telefone, carta, Internet, etc.).

Pretendemos, com este artigo, defender a idéia de que, independente das dificuldades inerentes ao Ensino a Distância (algumas já citadas) e das diferenças do tratamento que existem em comparação com o ensino presencial, em essência, não são necessárias novas concepções de ensino para se entenderem as necessidades de se aprofundar o olhar sobre a educação para se ensinar a distância. Com essa intenção, apresentamos e discutimos alguns conceitos pedagógicos básicos amplamente difundidos na área da Educação (em geral) e como os mesmos aparecem no Ensino a Distância a partir de reflexões de profissionais que já trabalham nessa modalidade. Longe de pretender exaltar as muitas dificuldades que, naturalmente, aparecem quando optamos pelo ensino não-presencial, esse artigo tenta mostrar que essa modalidade, conquanto oferece muitos desafios novos aos educadores, se tivermos clareza do que significa ensinar e competência para superar os obstáculos que se apresentam, estaremos oferecendo novas perspectivas no caminho de solucionar alguns problemas que existem para se conseguir educar nossa população.

O estudo que levou à produção deste artigo foi elaborado pela leitura de livros e artigos que tratam do ensino no sentido lato e de publicações recentes que tratam especificamente do Ensino a Distância.

Nas quatro seções seguintes, apresentamos algumas reflexões na direção de defender que o que está posto, realmente, de novo com o Ensino a Distância é uma nova situação desafiadora que exige, em essência, que os professores que com ela se envolvam tenham clareza de que o desafio deve ser encarado de frente, uma vez que a demanda por isso existe, e que devem se adaptar, como já apregoado nas mais recentes teorias de ensino/aprendizagem, às condições novas postas por essa nova modalidade. 


\section{Educação e Ensino a Distância}

No livro "Educação a Distância: construindo significados" (Preti, 2000), o artigo intitulado "Modelos de Educação a Distância" (Rodrigues, 2000) apresenta diversos modelos de ensino não presencial. A descrição desses modelos nos indicou, subjacentemente, que todos têm um "esqueleto" comum: (1) determinação das necessidades (público-alvo,objetivos); (2) organização e desenvolvimento do conteúdo (materiais e métodos); (3) avaliação (da aprendizagem e do próprio processo de ensino); (4) regulação (da aprendizagem e do processo de ensino). Essa estrutura é cíclica (reiniciando, a partir do (4), o (1) novamente).

O que salientamos é que essa estrutura também é básica no ensino presencial. É esperado que o professor, antes de organizar e desenvolver suas aulas, conheça (de preferência, profundamente) seus alunos. Um próximo passo natural no processo é o de avaliação (tanto da aprendizagem dos alunos quanto das próprias estratégias que o professor usou). A regulação, naturalmente seguinte, tem base no que foi e no que não foi alcançado no processo. É desejável que a regulação da aprendizagem seja feita pelo próprio aluno, o que depende tanto da qualidade do planejamento das aulas como do tipo de conceitos que o aluno estará estudando. As alterações necessárias para que o ensino ocorra de forma melhor numa próxima vez são levadas a cabo pelos responsáveis por todo o processo - o professor e a organização onde ele trabalha.

Uma das características da EaD que exige uma postura especial dos profissionais envolvidos é a de que eventuais mudanças durante o processo de aprendizagem, embora pudessem ser bem vindas, são, muitas vezes, de difícil implementação, uma vez que a troca de informações com os alunos não é imediata. Assim, o planejamento das aulas em EaD parece ter um papel maior do que no ensino presencial. Outra dessas características é a que, necessariamente, profissionais de diversas áreas deverão estar trabalhando, juntos, no processo. Na eventualidade de um trabalho desses, os professores têm uma chance de aprenderem, na prática, o que representa a interdisciplinaridade e como ela se insere no ensino.

O ensino tradicional nas universidades tem como base a organização do conhecimento de maneira encadeada, como se os conceitos que estivessem antes na cadeia devessem naturalmente ser tratados antes dos demais, que dos primeiros derivariam. Com as novas tecnologias disponíveis e a intensificação do uso das mesmas pela educação (particularmente, a internet e os hipertextos), cada vez mais a organização do conhecimento se mostra mais permeável dentro do conceito de rede. Compreender que uma boa metáfora para representar a organização do conhecimento humano é a rede ajuda na compreensão de como se pode trabalhar de forma interdisciplinar, entendendo que, em maior ou menor grau, todas as áreas de conhecimento estão relacionadas. Mais que isso, que algumas dessas relações podem representar a essência de alguns conceitos que se está estudando.

Apresentamos, nas três seções seguintes, aspectos básicos da educação, independendo se ela ocorre com ou sem a proximidade entre professores e alunos. Nelas, procuramos deixar evidente que a Ensino a Distância, enquanto nos coloca diante de grandes desafios, representa uma nova modalidade de como se pode ensinar e que, por ser nova e desafiadora, exige, essencialmente, que o professor com ela envolvido esteja preparado para um aprendizado constante e engajado com as orientações que nos oferecem concepções de vanguarda do que seja educar. Entendemos, aqui, como concepções de vanguarda as subjacentes no "Dez novas competências para ensinar" (Perrenoud, 2000), no "O ensino na escola" (Saint-Onge, 1999) e no livro "Educação e conhecimento" (Demo, 2000). 
Apresentamos, também nessas seções, algumas observações de profissionais que já trabalham há algum tempo em $\mathrm{EaD}$, para que seja estabelecido um claro elo entre elas e as idéias de Perrenoud, Saint-Onge e Demo. 


\section{O aluno como agente de sua própria aprendizagem}

Em qualquer processo educativo, as atividades, suas condições de execução e os conceitos que se deseja que os estudantes construam devem levar em conta principalmente o nível cognitivo em que esses se encontram, uma vez que uma falha nesse sentido pode levar a uma grande frustração ou decepção. Há, ainda, professores que tendem a pensar nos conceitos que devem ser trabalhados com seus alunos como algo pronto e acabado e que, por isso, é suficiente apresentá-los ao aluno que ele os absorverá.

\footnotetext{
"O saber não é algo pré-fabricado. Cada um precisa reconstruí-lo. O aluno necessita ser guiado na construção de seu saber. É a relação de mediação ${ }^{4}$ que assegura a qualidade do encaminhamento do aluno em sua busca do saber. Ao longo da interação que se estabelece entre a professora ou professor e o aluno, encontram-se atividades que visam aos processos intelectuais de pensamento e de raciocínio" (Saint-Onge, 1999).
}

Quando Cruz (1999) nos diz que é preciso que o professor domine a linguagem audiovisual não apenas como ferramenta, mas como a essência do seu modo de ensinar, está chamando a atenção para as reais condições para a aprendizagem no ensino a distância. Particularmente nesta modalidade, o planejamento das atividades que deverão levar os alunos a aprenderem precisa ser muito bem elaborado - "Na Educação a Distância, a improvisação é inaceitável" (Landim, 1997). Mesmo no ensino presencial, o planejamento é imprescindível. Embora possa ser, eventualmente, necessária alguma improvisação, ela não é desejável. Ela pode representar uma falha, por exemplo, no conhecimento das reais condições dos aprendizes pelo professor. Pode, também, representar uma deficiência na falta de previsão, pelo professor, das associações de conceitos que podem existir ou acontecer em fenômenos estudados pelos alunos, levando-os a uma demanda por algum nível de regulação que exija a mediação do professor para se operar.

Pensamos, como Bárcia et all. (2001), que o estudante é um agente capaz de entender os cenários em que está inserido, de estabelecer objetivos, de planejar estratégias, de desenvolver procedimentos para alcançar os resultados desejados. Este agente não pode ser entendido como um sujeito determinado pelo ambiente, mas, sim, como um indivíduo que pode superar as limitações do ambiente. Bárcia et all. observam que essa maneira de se entender o estudante é emergente (senão incipiente) no cenário da educação no Brasil.

Por outro lado, no ensino à distância, são exigidas estratégias de grande flexibilidade. De acordo com o perfil dos aprendizes, essas estratégias podem ser mais ou menos adequadas e eficientes. Existem alunos, por exemplo, que desenvolvem seu raciocínio melhor e mais rapidamente se aplicarem as idéias em situações práticas. Outros estudantes têm preferência por abstrações e teorizações. É possível que se encontrem perfis intermediários a esses dois. Alguns são mais autônomos que os outros, preferindo encarar desafios para construir, mais isolados dos demais, o conhecimento (Trindade, Carmo \& Bidarra, 2000). Esta flexibilidade também é desejável no ensino presencial, uma vez que as situações de aprendizagem devem ser ajustadas ao nível e às possibilidades dos alunos (Perrenoud, 2000).

Cruz e Bárcia sugerem-nos que essa flexibilidade pode passar pela oferta de atividades especiais:

${ }^{4} \mathrm{O}$ grifo é dos autores do presente artigo. V. $3 \mathrm{~N}^{\circ} 1$, Maio, 2005 
“...Dinâmicas que envolvam participação ativa dos alunos tais como seminários, debates, jogos, estudos de caso, demonstração, discussão, trabalho em grupo, palestrantes convidados e exercícios práticos podem ser utilizados de modo a tornar a aula mais interativa, produtiva e agradável para todos." Cruz e Bárcia (1999)

Rodrigues observa, citando Lévy (1993), que o conhecimento e o aprendizado estão associados aos valores e tecnologias de uma sociedade; que, com relação ao modo de transmitir/construir conhecimento, não se pode pensar numa única abordagem que seja pertinente a todas as situações. Num mesmo espaço geográfico podem apresentarse, simultaneamente, todas as tecnologias e economias dessa sociedade (Rodrigues, 2000). 


\title{
O professor como administrador da aprendizagem
}

Além de conceber, construir, organizar e gerenciar situações de ensino ajustadas às condições cognitivas prévias dos alunos, o professor precisa saber acompanhar o desenvolvimento das atividades pelos alunos. Esse acompanhamento, no caso do ensino a distância, não poderá acontecer durante a quase totalidade do tempo das atividades dos alunos. Isso exigirá do professor um conhecimento ainda maior de seus alunos e uma análise mais cuidadosa do retorno que esses alunos lhe darão em comunicações posteriores às atividades. Essas observações devem oferecer subsídios para a avaliação tanto do que os alunos estão aprendendo como da própria estratégia e administração da mesma pelo professor. Essas avaliações ajudarão o professor a planejar a orientação que fará a alunos nos seus estudos individuais e em grupos.

\begin{abstract}
... Assim como o médico, uma vez prescrita a medicação, colabora para o bom funcionamento do processo de cura sem controlar cada etapa dele, também o professor colabora para o processo de aprendizagem sem ter de controlar em detalhes as etapas das transformações cognitivas que se produzem nos alunos ${ }^{5}$. Ele identifica uma série de atividades suscetíveis de ativar os mecanismos necessários e as organiza. Entre essas atividades, há aquelas que não precisam de controle quando de sua execução : são as atividades de estudo. Essas atividades estão diretamente ligadas à aprendizagem; fazem parte integrante do ensino; são necessárias para que as transformações que têm lugar na sala de aula aconteçam. Eis a razão por que devem ser previstas, planejadas, organizadas, sustentadas por instruções claras e documentos de trabalhos apropriados (Saint-Onge, 1999).
\end{abstract}

Embora Saint-Onge não estivesse tratando especificamente do ensino a distância, a parte grifada apresenta-nos uma clara indicação da aplicabilidade dessa visão em $\mathrm{EaD}$.

Pedro Demo, em Educação \& Conhecimento, ressalta uma das conclusões a respeito da educação na atualidade:

"Um dos resultados mais contundentes é o reconhecimento de que, para o aluno aprender bem, mister se faz que o professor aprenda bem. Professor não é quem dá aula, mas quem sabe fazer o aluno aprender ${ }^{6}$. Metodologias básicas da aprendizagem parecem ser pesquisa e elaboração próprias, não processos instrucionais de treinamento. Professor como profissional da aprendizagem, não do ensino, pode significar guinada na teoria e na prática da educação" (Demo, 2000).

Para que o professor leve os alunos a aprenderem a aprender, é mister que ele próprio tenha essa capacidade. Professores que se envolvem com o ensino não presencial precisam desenvolver competências na direção do uso de outras linguagens para se adequar às características dos meios de comunicação que irá utilizar; precisam, também, rever suas concepções de ensino à luz das limitações nas condições de comunicação com seus alunos (Cruz, 2002).

\footnotetext{
${ }^{5}$ Grifo dos autores do presente artigo.

${ }^{6}$ Grifo dos autores do presente artigo.

V. $3 \mathrm{~N}^{\circ} 1$, Maio, 2005
} 


\title{
Novas tecnologias e o trabalho em equipe
}

Cruz e Bárcia, em artigo sobre Educação a Distância por videoconferência, apresentado no Congresso Brasileiro de Engenharia em 1999, identificaram algumas competências que o professor precisa desenvolver para trabalhar com videoconferência:

\begin{abstract}
“a) planejamento e organização dos cursos; b) habilidades de apresentação verbais e não verbais; c) conhecimento sobre como incentivar trabalho colaborativo em grupo; d) dominar estratégias de questionamento; e) possuir profundo conhecimento sobre o conteúdo da disciplina; f) saber como envolver estudantes e coordenar suas atividades a distância nos diferentes locais; g) possuir um conhecimento básico sobre teorias de aprendizagem; h) dominar um conhecimento sobre o campo do ensino a distância; i) ser capaz de desenvolver guias de estudo relacionado ao que vai na tela da televisão; $\mathrm{j}$ ) desenvolver um raciocínio gráfico e pensar visualmente." (CRUZ e BÁRCIA, 1999).
\end{abstract}

Observamos que os itens que poderiam caracterizar alguma especificidade com relação ao a distância seriam os de (f) a (j). É necessário saber envolver os alunos, independente de onde isso deve acontecer. Mesmo no ensino presencial isso é de extrema importância, como bem chama a atenção Perrenoud (2000). Os outros itens dizem despeito ao ambiente de trabalho do professor e as ferramentas de que dispõe para comunicação com seus alunos, o que, também, é importante no ensino presencial.

Perrenoud (2000) também observa a necessidade do professor desenvolver competências para explorar as potencialidades didáticas oferecidas pelas novas tecnologias, utilizando programas de computador que oferecem situações de aprendizagem aos estudantes, comunicando-se a distância por meios eletrônicos e utilizando ferramentas multimídia no ensino.

Perrenoud também salienta a importância do professor saber trabalhar em equipes, respeitando os papéis de cada um e oferecendo suas potencialidades ao apoio de projetos de ensino (2000).

Segundo Bates (1997) (in RODRIGUES, 2000), “a opção do uso de tecnologias de comunicação requer mudanças estruturais e organizacionais, para que os recursos disponibilizados possam se utilizados em todo o seu potencial".

Consideremos, num primeiro momento, que um determinado professor esteja engajado num projeto de ensino a distância. Para simplificarmos, vamos supor a disponibilidade de um dos seguintes meios de comunicação: impressos, vídeo, áudio, redes de computadores. Quaisquer que sejam os meios, tanto a preparação de materiais para o uso, quanto a implementação e manutenção dessa atividade requer o envolvimento de profissionais de diversas áreas (artes, comunicação ou eletrônica, etc.). Nesses casos, o professor precisa estar extremamente bem preparado para o trabalho em equipe. 


\section{Conclusão}

A partir das reflexões feitas nas quatro seções anteriores, concluímos que o importante para o professor engajar-se no trabalho de ensino a distância é que ele leve a fundo as orientações que as teorias de ensino/aprendizagem já nos trazem há muito tempo. O conhecimento profundo do que tem para ensinar, da realidade a sua volta (do aluno, dele próprio e do contexto onde estão) é imprescindível para que ele realize um bom trabalho. Deve planejar cuidadosamente suas aulas e estar apto a trabalhar com colegas professores técnicos de outras áreas do conhecimento.

Para isso, é importante que o professor esteja sempre se atualizando, tanto na utilização de novas tecnologias, quanto nos estudos de como elas podem ajudar nos processos educativos.

Assim, ao invés de interpretar a condição do Ensino a Distância como algo impossível de ser feito com eficiência ou como algo inadequado, se levarmos em conta as reflexões apresentadas, podemos interpretar essa condição como um novo trabalho educativo a ser feito sob condições menos favoráveis (em alguns aspectos) do que a educação tradicional e que oferece um novo e estimulante desafio a ser enfrentado pelos profissionais de ensino. 


\section{Referências Bibliografias}

ALONSO, Kátia Morosov. A educação à distância e um programa institucional de formação de professores em exercício. In: PRETTI, Oreste (Org.). Educação à Distância: construindo significados. Cuiabá:NEAD/IE-UFMT; Brasília:Plano, 2000

ARAÚJO, Carlos Henrique \& Nildo, Luzio. Dificuldades no ensino da matemática. http://www.inep.gov.br/imprensa/artigos/dificuldades_ensino_matematica.htm. Acesso em 10 de junho de 2004 às 20 h35min.

BÁRCIA, Ricardo; VIANNEY, João; RODRIGUES, Rosângela; MORAES, Marialice de; SPANHOL, Fernando; BITTENCOURT, Dênia de.. Graduate studies at a distance: the construction of a brazilian model. In: Tschang, F. T. and Della Senta, T. 1. Access to Knowledge; New Information Technologies and The Emergence of the Virtual University. UNU/IAS. Permgamon Press, 2001

BONAMINO, Alícia e FRANCO, Creso. Avaliação e política educacional: O processo de institucionalização do SAEB. Cadernos de Pesquisa, n.108, p.101-132, novembro, 1999.

CRUZ, Dulce Márcia \& BARCIA, Ricardo Miranda. Educação à distância por videoconferência. Congresso Brasileiro de Engenharia, 1999.

CRUZ, Dulce Márcia. O professor midiático: a formação docente para a educação à distância no ambiente virtual da videoconferência. Salvador: XXV Congresso Intercom, 2002

DEMO, Pedro. Educação e conhecimento. Petrópolis, RJ: Ed. Vozes, 2000.

INEP - INSTITUTO NACIONAL DE ESTUDOS E PESQUISAS EDUCACIONAIS. Net, Brasília(DF). Seção Censo. Disponível em: http://www.inep.gov.br/censo/default.htm. Acesso em: 27 de julho de 2001 às 19h30min.

LANDIM, C. M. das M. P. F. Educação à distância: algumas considerações. Rio de Janeiro: [s.n.], 1997

LÉVY, Pierre. Tecnologias da inteligência: o futuro do pensamento na era da informática. Trad. Carlos Irineu da Costa. Rio de Janeiro: Ed. 34, 1993

PHILIPPE PERRENOUD, Philippe. Dez novas competências para ensinar. Porto Alegre: Artes Médicas Sul, 2000.

PRETI, Oreste (org.). Educação à Distância: construindo significados. Cuiabá:

NEAD/IE-UFMT; Brasília: Plano, 2000

PRETI, Oreste (org.). Educação à Distância: inícios e indícios de um percurso. Cuiabá: NEAD/IE-UFMT; Brasília: Plano, 1996

RODRIGUES, Rosângela Schwarz. Modelos de educação à distância. In: PRETI, Oreste (org.). Educação à Distância: construindo significados. Cuiabá: NEAD/IEUFMT; Brasília: Plano, 2000

SAINT-ONGE, Michel. O ensino na escola. São Paulo: Edições Loyola, 1999.

SHALE, Dong. Toward a reconceptualization of distance education. In:MOORE, M. et al. Contemporary issues in american distance education. New York: Pergamon Press, 1990. P. 533-543) 
$-\curvearrowright$ CINTED-UFRGS

TRINDADE, A. R.; CARMO, H.; BIDARRA, J.. Current developments and best practice in open and distance learning. International Review of Research in Open and Distance Learning. ISSN: 1942-3831. Vol. 1, No. 1, 2000 